\title{
Isotope-Reinforced Polyunsaturated Fatty Acids Protect Yeast Cells from Oxidative Stress
}

\author{
Shauna Hilla ${ }^{\text {, Kathleen Hirano }}{ }^{a}$, Vadim V. Shmanai ${ }^{b}$, Beth N. Marbois ${ }^{a}$, Dragoslav \\ Vidovic $^{\mathrm{C}}$, Andrei V. Bekish ${ }^{\mathrm{d}}$, Bradley Kay ${ }^{\mathrm{a}}$, Vincent Tse ${ }^{\mathrm{a}}$, Jonathan Fine ${ }^{\mathrm{a}}$, Catherine F.

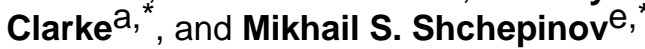 \\ a Department of Chemistry and Biochemistry and the Molecular Biology Institute, University of \\ California, Los Angeles, Los Angeles, CA 90095 \\ b Institute of Physical Organic Chemistry of the National Academy of Sciences of Belarus, 13 \\ Surganova Street, 220072 Belarus \\ c Department of Chemistry, Oxford University, South Parks Road, Oxford OX1 3QR, UK \\ d Department of Chemistry, Belarussian State University, Minsk 220030 Belarus \\ e Retrotope, Inc. 12133 Foothill Lane, Los Altos Hills, CA 94022, USA
}

\begin{abstract}
The facile abstraction of bis-allylic hydrogens from polyunsaturated fatty acids (PUFAs) is the hallmark chemistry responsible for initiation and propagation of autoxidation reactions. The products of these autoxidation reactions can form cross-links to other membrane components, damage proteins and nucleic acid. We report that PUFAs deuterated at bis-allylic sites are much more resistant to autoxidation reactions, due to the isotope effect. This is shown using coenzyme Q-deficient Saccharomyces cerevisiae coq mutants with defects in biosynthesis of coenzyme Q (Q). Q functions in respiratory energy metabolism and also functions as a lipid-soluble antioxidant. Yeast coq mutants incubated in the presence of the PUFAs $\alpha$-linolenic or linoleic acid exhibit $99 \%$ loss of colony formation after four hours, demonstrating a profound loss of viability. In contrast, $\operatorname{coq}$ mutants treated with monounsaturated oleic acid or with one of the deuterated PUFAs:11,11- $\mathrm{D}_{2}$-Linoleic or $11,11,14,14-\mathrm{D}_{4}-\alpha$ Linolenic retain viability similar to wild-type yeast. Deuterated PUFAs also confer protection to wild-type yeast subjected to heat stress. These results indicate that isotope-reinforced PUFAs are stabilized compared to standard PUFAs, and they protect coq mutants and wild-type yeast cells against the toxic effects of lipid autoxidation products. These findings suggest new approaches to controlling ROS-inflicted cellular damage and oxidative stress.
\end{abstract}

\section{Keywords}

Isotope Effect; Lipid Autoxidation; Oxidative Stress; Coenzyme Q; Ubiquinone

\footnotetext{
*To whom correspondence should be addressed: Catherine F. Clarke, UCLA Department of Chemistry and Biochemistry, 607 Charles E. Young Dr. E., Los Angeles CA 90095 Tel (310) 825-0771; Fax (310) 206-5213; cathy@ chem.ucla.edu; and Mikhail S. Shchepinov, Retrotope, Inc. 12133 Foothill Lane, Los Altos Hills, CA 94022, USA (650)-917-9256; Fax (650)-917-9255; misha@retrotope.com.

Publisher's Disclaimer: This is a PDF file of an unedited manuscript that has been accepted for publication. As a service to our customers we are providing this early version of the manuscript. The manuscript will undergo copyediting, typesetting, and review of the resulting proof before it is published in its final citable form. Please note that during the production process errors may be discovered which could affect the content, and all legal disclaimers that apply to the journal pertain.
} 


\section{Introduction}

Autoxidation of polyunsaturated fatty acids (PUFAs), or lipid peroxidation is a consequence of life in an oxygen-enriched atmosphere. This process is detrimental to the cell and has been linked to age-related degenerative diseases [1-3] and is associated with apoptosis [4]. However, PUFAs such as linoleic acid (Lin; 18:2, n-6) and alpha linolenic acid ( $\alpha$ Lnn; 18:3, n-3) are essential fatty acids for humans and many animals, and are important constituents of membranes. Mitochondrial membranes are particularly enriched in PUFAs, which are present in $80 \%$ of the total phospholipids. PUFAs are vital for optimal function of respiratory electron transport and oxidative phosphorylation, but are easily damaged, reacting with reactive oxygen species (ROS) through a chain reaction mechanism [5] (Fig. 1). In addition to deteriorating membrane fluidity [6], oxidized PUFAs relay oxidative damage to other biomolecules, most notably proteins and DNA [7], through reactive carbonyl compounds such as malondialdehyde (MDA), 4-hydroxy-nonenal (HNE), and 4hydroxy-hexenal (HHE). HNE and HHE are both small molecule 4-hydroxy-alkenals, but have profound differences in solubility and react distinctly with phospholipid and protein targets [8-10].

Lipid oxidation can have significant downstream effects and possibly play a major role in cell signalling pathways. For example, the mitochondria-specific lipid, cardiolipin makes up $18 \%$ of the total phospholipids, and $90 \%$ of the fatty acyl chains are unsaturated (primarily Lin) [2]. Oxidation of cardiolipin may be one of the critical factors initiating apoptosis by liberating cytochrome $c$ from the mitochondrial inner membrane and facilitating permeabilization of the outer membrane $[4,11]$. The release of cytochrome $c$, in turn, activates a proteolytic cascade that culminates in apoptotic cell death [12].

The success of antioxidant therapies targeting oxidative damage of PUFAs has been limited. Indeed, much controversy surrounds the in vivo function of vitamin $\mathrm{E}$ as a chain terminating antioxidant [13]. The controversies and confusion surrounding antioxidant therapies may be due to several reasons, including: the near-saturating amount of antioxidants already present in living cells [14]; the importance of ROS in cell signalling [15] and other processes [16]; and the importance of low levels of ROS for hormetic (adaptive) upregulation of protective mechanisms [17]. In fact, the wide array of lipid autoxidation products constitutes a very complex assault that cannot be effectively neutralized by simple chain termination strategies. For example, reactive $\alpha, \beta$-unsaturated carbonyls formed by PUFA peroxidation are still capable of altering the cellular redox status by depleting cellular sulfhydryl compounds such as glutathione. The toxicity of oxidized forms of some antioxidants [14] may also be an important factor. The vitamin $\mathrm{E}$ radical itself can abstract hydrogen from PUFAs, albeit at a much lower rate compared to other ROS [5,18]. Antioxidants therefore provide a far from perfect defence against PUFA autoxidation.

The bis-allylic $\mathrm{H}$ atoms constitute the vulnerable sites of PUFA autoxidation [19]. Sitespecific "isotope reinforcement" of PUFAs at oxidation-prone bis-allylic sites (Fig. 1) has been hypothesized to slow down the ROS-driven autoxidation process [20,21], based on the primary kinetic isotope effect (IE). The vibration frequency of the chemical bond between two atoms depends on their masses. Thus, for different isotopes of the same element this vibration parameter will be different, affecting bond cleavage rates: heavier isotopes form stronger bonds. The rate of reaction involving $\mathrm{C}-\mathrm{H}$ bond cleavage is typically 5 to 10 times faster than the corresponding C-D bond cleavage, due to the two-fold difference in the masses of $\mathrm{H}$ and $\mathrm{D}$ [22]. ROS-mediated autoxidation reactions are a good illustration of the IE, since hydrogen abstraction by an oxidizer is usually the rate-limiting step [19]. IE values of 80-100 were obtained when hydrogen tunnelling was part of the enzymatic reaction 
mechanism $[23,24]$, while the IE for ROS-driven nonenzymatic oxidation of a bis-allylic $\mathrm{CH}_{2}$ group in solution was around six [25].

Here we validate this conjecture by making use of a coenzyme Q-deficient yeast model. Nine Saccharomyces cerevisiae genes (COQ1-COQ9) are required for biosynthesis of coenzyme $\mathrm{Q}$ (ubiquione or $\mathrm{Q}$ ) [26]. The hydroquinone form of $\mathrm{Q}$ (ubiquinol or $\mathrm{QH}_{2}$ ) is a lipophilic antioxidant as well as an essential electron shuttle in the respiratory chain of the inner mitochondrial membrane [27]. Yeast synthesize only saturated and monounsaturated palmitoleic (16:1, n-9) and oleic (Ole; 18:1, n-9) acids [28], which are resistant to lipid peroxidation [19]. However, $S$. cerevisiae readily take up exogenous PUFAs and incorporate them into glycerolipids (up to 50\%), with no apparent detrimental effects [28,29]. In contrast, the Q-less yeast (coq) mutants are exquisitely sensitive to treatment with exogenous PUFAs because they lack $\mathrm{Q} / \mathrm{QH}_{2}[30,31]$. $\mathrm{QH}_{2}$ acts as both a primary chainterminating antioxidant and as a co-antioxidant reducing the radical form of vitamin $\mathrm{E}$ [27]. In this study, we have compared the sensitivity of both wild-type yeast and the $c o q$ yeast mutants towards different PUFAs deuterated at bis-allylic sites, versus the standard (hydrogen-containing) PUFAs. The results show that site-specific deuterations substantially protect PUFAs from oxidation, suggesting new approaches to controlling ROS-inflicted cellular damage and oxidative stress.

\section{Materials and Methods}

\section{Synthetic methods}

MALDI-TOF mass-spectra were recorded on a PE-ABI Voyager Elite delayed extraction instrument. Spectra were acquired with an accelerating voltage of $25 \mathrm{KV}$ and $100 \mathrm{~ms}$ delay in the positive ion mode. HPLC was carried out on a Waters system. Chemicals were from Sigma-Aldrich Chemical Company (USA), Avocado research chemicals (UK), Lancaster Synthesis Ltd (UK), and Acros Organics (Fisher Scientific, UK). Silica gel, TLC plates and solvents were from BDH/Merck. IR spectra were recorded with Vertex 70 spectrometer. ${ }^{1} \mathrm{H}$ and ${ }^{13} \mathrm{C}$ NMR spectra were obtained with a Bruker AC 400 instrument at 400 and $100 \mathrm{MHz}$ respectively, in $\mathrm{CDCl}_{3}$ (TMS at $\delta=0.00$ or $\mathrm{CHCl}_{3}$ at $\delta=7.26$ for ${ }^{1} \mathrm{H}$ and $\mathrm{CHCl}_{3}$ at $\delta=77.0$ for ${ }^{13} \mathrm{C}$ as an internal standard). The synthesis of each of the deuterated PUFAs (Fig. 1) was performed with modificiations of published protocols [32-34] and is described in Supplementary Material.

\section{Yeast Strains and media}

Yeast strains included the wild-type, W303-1A (MAT a ade2-1 his3-1,15 leu2-3,112 trp1-1 ura3-1) [30]; a coq3 null mutant, CC303 (MAT $\alpha$ ade2-1 his3-1,15 leu2-3,112 trp1-1 ura3-1 coq3::LEU2) [30]; a coq7 null mutant, W303 $\triangle \mathrm{COQ} 7$ (MAT $\alpha$ ade2-1 his3-1,15 leu2-3,112 trp1-1 ura3-1 coq7::LEU2) [35]; a coq9 null mutant, W303 $\triangle$ COQ9 (MAT $\alpha$ ade2-1 his3-1,15 leu2-3,112 trp1-1 ura3-1 coq9::URA3) [36]; and an atp2 null mutant, W303 $\triangle$ ATP2 (MAT a ade2-1 his3-1,15 leu2-3,112 trp1-1 ura3-1 atp2::LEU2) [30]. Media were prepared as described [37] and included YPD (1\% yeast extract, $2 \%$ yeast peptone, $2 \%$ dextrose), YPG (1\% yeast extract, $2 \%$ yeast peptone, $3 \%$ glycerol), and YPE (1\% yeast extract, $2 \%$ yeast peptone, $2 \%$ ethanol). Solid plate medium contained $2 \%$ bacto agar. Media components were obtained from Difco, Fisher, and Sigma.

\section{Fatty acid sensitivity assays}

Fatty acids Ole, Lin, and $\alpha \operatorname{Lnn}$ (99\% pure) were from Sigma/Aldrich. A fatty acid sensitivity assay was used to assess relative sensitivities of different yeast mutants to oxidative stress $[30,31]$. Yeast strains were grown in YPD media at $30^{\circ} \mathrm{C}$ and $250 \mathrm{rpm}$ and harvested while in logarithmic phase $\left(\mathrm{OD}_{600 \mathrm{~nm}}=0.1-1.0\right)$. The cells were washed twice with sterile water 
and resuspended in $0.10 \mathrm{M}$ phosphate buffer, $\mathrm{pH} 6.2$ with $0.2 \%$ dextrose, to an optical density of $0.20 \mathrm{OD}_{600 \mathrm{~nm}}$. Aliquots $(20 \mathrm{ml})$ were placed in new sterile flasks $(125 \mathrm{ml})$ and fatty acids were added to a final concentration of $200 \mu \mathrm{M}$ (from stocks prepared in ethanol). Following incubation $\left(30^{\circ} \mathrm{C}\right.$ and $\left.250 \mathrm{rpm}\right)$ aliquots were removed and viability was ascertained by either colony counting [30] or by plate dilution assays. Plate dilution assays were performed by spotting $2 \mu \mathrm{l}$ of $1: 5$ serial dilutions (starting at $0.20 \mathrm{OD} / \mathrm{ml}$ ), onto the designated plate medium. Pictures were taken after two or three days of growth at $30^{\circ} \mathrm{C}$.

\section{Fatty acid uptake and GC-MS detection of fatty acids}

Wild-type (W303) yeast were harvested at log phase, and resuspended in phosphate buffer ( $0.10 \mathrm{M}$ sodium phosphate, $\mathrm{pH} 6.2,0.2 \%$ dextrose) as described for the fatty acid sensitivity assay. Cells $\left(0.20 \mathrm{OD}_{600 \mathrm{~nm}}\right)$ were incubated in the presence of $200 \mu \mathrm{M}$ of the designated fatty acid for either 0 or $4 \mathrm{~h}$. Samples were prepared in duplicate as independent replicates of single fatty acid treatment conditions. Yeast cells were collected by centrifugation $(1000 \times$ $g, 5 \mathrm{~min}$ ), washed twice with sterile water and the yeast cell pellets were stored at $-20^{\circ} \mathrm{C}$ (borosilicate centrifuge tube with screw cap) until further processing. Saponification, lipid extraction and alkaline methanolysis were performed as described $[38,39]$ with the following modifications. Yeast cell pellets $\left(10 \mathrm{OD}_{600 \mathrm{~nm}}\right)$ were resuspended in $1 \mathrm{ml} 20 \%$ (w/ v) $\mathrm{KOH}$ in $1: 1$ methanol:water in tightly capped borosilicate tubes and incubated in a $100^{\circ} \mathrm{C}$ water bath for $1 \mathrm{~h}$. Tubes were transferred to ice, allowed to cool, and debris sedimented by centrifugation $(1000 \times g, 5 \mathrm{~min})$. Supernatants were transferred to new borosilicate tubes and were acidified to $\mathrm{pH} 2$ with 10 drops of $6 \mathrm{~N} \mathrm{HCl} \mathrm{(37.6 \% )} \mathrm{followed} \mathrm{by} \mathrm{the} \mathrm{addition} \mathrm{of} 2$ $\mathrm{ml}$ of boron trifluoride-methanol (Sigma). Samples were incubated for $5 \mathrm{~min}$ in a $100^{\circ} \mathrm{C}$ water bath, placed on ice and extracted. Heptadecanoic acid (C17:0, $200 \mu \mathrm{g})$ was added to every sample of saponified yeast cellular extract before addition of boron trifluoride methanol. Fatty acid methyl esters were extracted with $1 \mathrm{ml}$ of saturated sodium chloride and $2 \mathrm{ml}$ of 1:4 (v/v) chloroform:hexanes. The upper organic layer was transferred to a new borosilicate tube and dried under a stream of nitrogen gas. A calibration curve was prepared concurrently and contained the internal standard and each analyte in the following amounts: $10,50,100,200$, and $500 \mu \mathrm{g}$. The lipid extracts of the samples and standards were concentrated under nitrogen gas, stored at $-20^{\circ} \mathrm{C}$, and resuspended in $50 \mu \mathrm{l}$ of ethyl acetate just before analysis by GC-MS.

Samples were subjected to analyses by GC-MS (Agilent 6890-6975) with a DB-wax column $(0.25 \mathrm{~mm}$ inner diameter $\times 30 \mathrm{~m}$ length $\times 0.25-\mu \mathrm{m}$ film thickness) (Agilent catalog number 122-7032). Temperature program was $100^{\circ} \mathrm{C}$ to $250^{\circ} \mathrm{C}$ over $23 \mathrm{~min}, 1 \mu \mathrm{l}$ was injected, with a split ratio of 1:80. Peak areas of extracted ion chromatograms for each analyte and the heptadecanoic acid internal standard were exported to Microsoft Excel and the slope from the calibration curve was used to derive the amounts of fatty acid taken up by the treated yeast. Data represented in chromatograms describes the area detected via the molecular ion of the selected fatty acid methyl ester molecular ions $[\mathrm{M}]+$ as follows: heptadecanoic (C17:0) $\mathrm{m} / \mathrm{z} 284.3$ [internal standard]; Ole m/z 296.3; Lin m/z 294.3; $\alpha \mathrm{Lnn} \mathrm{m} / \mathrm{z} 292.2 ; \mathrm{D}_{2^{-}}$ Lin $\mathrm{m} / \mathrm{z} 296.3$ and $\mathrm{D}_{4}-\alpha \mathrm{Lnn} \mathrm{m} / \mathrm{z}$ 296.3. Extracted ion chromatograms allowed selective integration of the overlapping Lin and $\mathrm{D}_{2}$-Lin retention times. Analyses performed by extraction of the molecular ions were indistinguishable from analyses that relied on total ion chromatograms.

\section{Rescue of PUFA sensitivity with exogenous antioxidants}

Yeast strains were harvested at $\log$ phase, and resuspended in phosphate buffer $(0.10 \mathrm{M}$ sodium phosphate, $\mathrm{pH} 6.2,0.2 \%$ dextrose) as described for the fatty acid sensitivity assay. Cells $\left(0.20 \mathrm{OD}_{600 \mathrm{~nm}}\right)$ were treated with $200 \mu \mathrm{M}$ of butylated hydroxy toluene (Fluka), Vitamin E (Sigma) or the more soluble vitamin E analog, Trolox (Caymen Chemicals) prior 
to the addition of $200 \mu \mathrm{M}$ of the designated fatty acid followed by incubation. Cell viability was assessed by colony count.

\section{Preparation of protein extracts}

Yeast coq3 null mutants were harvested at log phase, and resuspended in phosphate buffer ( $0.10 \mathrm{M}$ sodium phosphate, $\mathrm{pH} 6.2,0.2 \%$ dextrose) as described for the fatty acid sensitivity assay. Cells $\left(0.20 \mathrm{OD}_{600 \mathrm{~nm}}\right)$ were incubated in the presence of $200 \mu \mathrm{M}$ of the designated fatty acid for $2 \mathrm{~h}$. Yeast cell pellets $\left(20 \mathrm{OD}_{600 \mathrm{~nm}}\right)$ were collected as described for the fatty acid uptake and GC-MS detection of fatty acids. Protein extraction and derivatization were performed as described [40] with the following modifications. Yeast cell pellets were resuspended in $100 \mu \mathrm{L}$ of $10 \%$ glycerol, 2 mM EDTA and $1 \mathrm{mM}$ protease inhibitor (Roche) and transferred to microcentrifuge tubes. Acid washed glass beads $(175 \mathrm{mg})$ were added, and cells were lysed by vortexing ( 5 cycles, $20 \mathrm{~s}$ vortex, $20 \mathrm{~s}$ on ice). The supernatant was collected by centrifugation $\left(18,000 \times g, 30 \mathrm{~min}, 4^{\circ} \mathrm{C}\right)$, transferred to a new microcentrifuge tube, and glass beads were washed once with $50 \mu \mathrm{L}$ of $10 \%$ glycerol, 2 mM EDTA and 1 $\mathrm{mM}$ protease inhibitor followed by an identical round of centrifugation. The supernatants were quantified for protein content using a BCA protein assay kit (Thermo Scientific) and then stored at $-20^{\circ} \mathrm{C}$ until assayed for HNE-protein adducts.

\section{Results}

\section{Synthesis of site specifically deuterated PUFAs}

We used monounsaturated oleic acid (Ole; 18:1, n-9); linoleic acid (Lin; 18:2, n-6); and linolenic acid ( $\alpha$ Lnn, 18:3, n-3), hydrogenated or deuterated at bis-allylic positions (Fig. 1). Modifications of the published protocols [32,33] were used to synthesize 11,11- $\mathrm{D}_{2}$-Lin. Syntheses of $11,11-\mathrm{D}_{2}-\alpha \mathrm{Lnn}, 14,14-\mathrm{D}_{2}-\alpha \mathrm{Lnn}$, and $11,11,14,14-\mathrm{D}_{4}-\alpha \mathrm{Lnn}$ were carried out with modifications of an earlier described method [34], as described in Supplementary Material. The structures and purity of deuterated PUFAs were confirmed by ${ }^{1} \mathrm{H}$ and ${ }^{13} \mathrm{C}$ NMR (Fig. 2).

\section{GC-MS separation and yeast uptake of PUFAs}

Yeast take up exogenous PUFAs and incorporate them into phospholipids [28,29]. We expected that deuterated PUFAs would also be readily taken up by yeast, as the bis-allylic positions are not involved in incorporation reactions. To validate this, the extent of uptake of Lin, $\mathrm{D}_{2}$-Lin, $\alpha \operatorname{Lnn}$ and $\mathrm{D}_{4}-\alpha \mathrm{Lnn}$ was monitored by GC-MS. We first determined conditions of separation of fatty acid methyl esters (FAME) of Ole, Lin, $\mathrm{D}_{2}$-Lin, $\alpha \mathrm{Lnn}, \mathrm{D}_{4}-\alpha \mathrm{Lnn}$, and C17:0 (heptadecanoic acid, used as an internal standard). The GC-MS chromatogram established both separation and sensitivity of detection of these fatty acid methyl ester standards. The fatty acids from WT (W303) yeast are detected as FAMEs following GC-MS (Fig. 3A). The amounts of Lin, $\mathrm{D}_{2}$-Lin, $\alpha \operatorname{Lnn}$ and $\mathrm{D}_{4}-\alpha \operatorname{Lnn}$ detected after $4 \mathrm{~h}$ incubation (determined from the calibration curve) indicate that yeast avidly uptake each of these PUFAs during the $4 \mathrm{~h}$ incubation period (Fig. 3B).

\section{Q-less yeast (coq mutants) provide a simple model to assess in vivo autoxidation of fatty acids}

Previous studies have shown the coq yeast mutants are hypersensitive to treatment with PUFAs [30,31]. Yeast coq mutants treated with $\alpha$ Lnn show a profound decrease in viability as revealed by plating dilutions of cells onto rich growth medium (Fig. 4). The sensitivity of the different strains can be observed by visual inspection of the density of cells in each spot. The hypersensitivity of the Q-less yeast mutants is not a secondary effect of the inability to respire because atp 2 mutant yeast (lacking the ATP synthase) show wild-type resistance to 
PUFA treatment (Fig. 4) [30,31]. In contrast, the coq mutants show enhanced viability following treatment with the isotope- reinforced $11,11,14,14-\mathrm{D}_{4}-\alpha \mathrm{Lnn}$, indicating this isotope reinforced PUFA is much less toxic to the coq mutants.

In order to assess the number of viable cells remaining following treatment with the different PUFAs, samples of yeast were examined by a colony counting assay, and the colony forming units determined. These assays revealed that the viability of cells treated with oleic acid and deuterated PUFAs was similar, while the viability of the coq 3 mutants was reduced more than 100-fold following treatment with $\alpha \mathrm{Lnn}$ for $4 \mathrm{~h}$ (Fig. 5). The viability of the coq mutants was reduced more than 100-fold following treatment with Lin, and more than 1000-fold following treatment with $\alpha \mathrm{Lnn}$, for $10 \mathrm{~h}$ (Fig. 6). Thus, treatment with either Lin or $\alpha \mathrm{Lnn}$ acids causes dramatic loss of viability of the coq null mutants. In stark contrast, coq mutants treated with any of the deuterated PUFAs retain viabilities similar to yeast treated with oleic acid. These results indicate that isotope-reinforced PUFAs are much more resistant to autoxidation than are the standard PUFAs, as evidenced by the resistance of the hypersensitive coq mutants to cell killing.

\section{Hypersensitivity of coq3 mutant yeast to PUFA treatment is rescued by antioxidants}

The ability of free radical scavengers to protect yeast coq mutants from PUFA-mediated oxidative stress provided strong evidence that autoxidation products of PUFAs were responsible for initiating cell killing [30]. To determine whether antioxidants showed similar efficacy in the present experiments, butylated hydroxy toluene (BHT), vitamin E, or trolox (a soluble analog of vitamin $\mathrm{E}$ ) were added to yeast immediately prior to the addition of either Lin (Fig. 7A) or $\alpha$ Lnn (Fig. 7B). Each of the antioxidants resulted in a dramatic increase in the number of survivors, indicating that the PUFA-mediated cell killing was rescued by a variety of chain-breaking antioxidants.

\section{Heat-stressed wild-type yeast are sensitive to treatment with standard- but not deuterated- PUFAs}

Wild-type yeast are not sensitive to treatment with PUFAs [30,31] when cultured under standard conditions and $30^{\circ} \mathrm{C}$. However, a substantial decrease in viability is evident when wild-type yeast are incubated with PUFAs at elevated temperatures $\left(37^{\circ} \mathrm{C}\right)$ (Fig. 8). The sensitivity of the wild-type yeast is likely due to the increased oxidative stress caused by elevated temperatures [41]. In contrast, wild-type yeast show enhanced viability following identical treatment with the isotope-reinforced $11,11-\mathrm{D}_{2}-\mathrm{Lin}, 11,11-\mathrm{D}_{2}-\alpha \mathrm{Lnn}, 14,14-\mathrm{D}_{4^{-}}$ $\alpha \mathrm{Lnn}$, or $11,11,14,14-\mathrm{D}_{4}-\alpha \mathrm{Lnn}$, indicating the isotope reinforced PUFAs are much less toxic to the wild-type yeast.

To examine whether the heat plus PUFA stress impaired mitochondrial function, wild-type yeast were plated onto media requiring fermentation or respiratory metabolism. The number of survivors was assessed following plating on rich media containing dextrose (YPD) as a fermentable carbon source, or ethanol, or glycerol (YPE or YPG, respectively) as nonfermentable carbon sources. The results indicate that the number of colony forming units observed on YPD plate media is indistinguishable when compared to any of the nonfermentable carbon sources (Fig. 9). The results suggest that heat plus PUFA stress impacts yeast cell viability as assayed on either fermentable or non-fermentable carbon sources. Because antioxidants rescued the sensitivity of heat stressed wild-type yeast treated with Lin (Fig. 10), it is apparent that autoxidation products of PUFAs were responsible for initiating cell killing in the heat-stressed wild-type yeast. 


\section{Discussion}

Of the many cellular components damaged by oxidative stress, PUFAs comprise some of the most sensitive and vulnerable cellular targets [42]. Generally, the rate of non-enzymatic, ROS-driven peroxidation of PUFAs increases with the degree of unsaturation of the fatty acid [3,25,43], although there are exceptions [44]. Initial steps of peroxidation are well understood, with hydrogen abstraction at position 11 of Lin being the rate-limiting first step $[19,45]$. For $\alpha$ Lnn, hydrogen abstraction can proceed at either position 11 or 14 . This is followed by the formation of hydroperoxides, and eventually results in generation of HNE or 2-hydroxyheptanal from Lin. $\alpha$ Lnn predominantly generates MDA (initial hydrogen abstraction at position 11), or HHE (abstraction at position 14) as major products [46]. These pathways are complex [47], and the exact mechanisms of formation of $\alpha, \beta$-unsturated carbonyl compounds or other reactive carbonyl compounds from PUFAs are still debatable [48-50]. Many other reactive products of PUFA peroxidation have been detected and differ in their toxicity [46].

PUFAs such as Lin and $\alpha$ Lnn are toxic to coq mutant (Q-deficient) yeast strains. This is due to autoxidation products of PUFAs that form in the absence of $\mathrm{Q} / \mathrm{QH}_{2}$, a lipid soluble chain terminating antioxidant [30]. The coq mutant cells can also be rescued by supplementation with a variety of other chain terminating antioxidants. In mammalian cells, Lin, $\alpha \mathrm{Lnn}$, and other PUFAs are substrates for complex enzymatic systems that oxidise PUFAs, converting them into a variety of lipid mediators. Both n-6 and n-3 PUFAs undergo such enzymatic transformations (cyclooxygenase pathway, lipoxygenase pathway, etc), giving rise to several classes of signalling moieties such as prostaglandins and leukotrienes [51]. S. cerevisiae lack these enzymatic oxidation pathways, and synthesize only monounsaturated fatty acids. However, $S$. cerevisiae readily take up exogenous free fatty acids by import and activation to form fatty acyl-CoAs, which are then used as substrates for lipid synthesis or in betaoxidation for energy production [52]. PUFA-supplemented yeast thus represents a simple model for studying ROS-driven peroxidation pathways.

We used the Q-less coq mutant yeast strains to test whether PUFA-induced oxidative stress could be allayed by deuterated PUFAs reinforced with heavy stable isotopes (deuterium atoms) at oxidation prone bis-allylic sites. The results show that $\mathrm{D}_{2}$-Lin and $\mathrm{D}_{4}-\alpha \mathrm{Lnn}$ are taken up by yeast with efficiency similar to that of hydrogen-containing (standard) PUFAs. No toxicity was observed, although it will be important to test this in an animal model. The toxicity of heavy water [53] is unlikely to be relevant in any case because it is associated with exchangeable protons. Non-exchangeable deuterium atoms are not toxic as long as they are not released in the form of $\mathrm{D}_{2} \mathrm{O}$ in high concentrations. Moreover, the Q-less yeast incubated with the site-specifically deuterated PUFAs no longer exhibit hypersensitivity. In fact, the Q-less yeast are as resilient to D-PUFAs as they are to treatment with Ole, a monounsaturated fatty acid known to be much less prone to autoxidation.

To further explore the site-specific reinforcement of $\alpha \mathrm{Lnn}$, derivatives of $\alpha \mathrm{Lnn}$ deuterated either at position 11 or 14 , were compared with the tetra-deuterated $11,11,14,14-\mathrm{D}_{4}-\alpha \mathrm{Lnn}$. Our finding that 11,11 - and $14,14-\mathrm{D}_{2}-\alpha \mathrm{Lnn}$ are similarly non-toxic as compared to $\mathrm{D}_{4}-\alpha \mathrm{Lnn}$ is consistent with the proposed mechanism of intermolecular cross-linking of PUFAs within the membrane [50]. Partial isotope protection of PUFAs should slow down this crosslinking, decreasing the lipid membrane damage and the reactive carbonyl formation. Individual yeast cells of the same culture are known to vary by up to 5-fold in their content of antioxidant proteins [54], and this might also make a 50\% difference in toxicity between $\mathrm{D}_{2}-\alpha \operatorname{Lnn}$ and $\mathrm{D}_{4}-\alpha \mathrm{Lnn}$ difficult to detect. However both $11,11-$ and $14,14-\mathrm{D}_{2}-\alpha \operatorname{Lnn}$ are profoundly protective as compared to Lin, even though these PUFAs have the same number of bis-allylic hydrogens. We note that the oxidation products formed by Lin (an n-6 PUFA) 
and $\alpha$ Lnn (an n-3 PUFA) are distinct, as Lin will generate 4-HNE while $\alpha$ Lnn will produce HHE [9,55]. Although both HNE and HHE are 4-hydroxy-2-alkenals, there is a growing body of evidence that HHE may have distinct biological effects as compared to 4-HNE [9]. 4-HNE is more reactive with phosphatidylethanolamine and forms protein adducts more readily than HHE $[8,10]$, while certain cellular targets seem more sensitive to HHE $[9,10]$. Since our assay is that of cell survival, it seems apparent that the differential cell killing is not a result of the number or even the placement of bis-allylic $\mathrm{H}$, but rather must derive from the interaction of particular autoxidation products (derived from $n-3$ and n-6 PUFAs) with cellular targets.

The protection observed in these studies is surprisingly robust as compared to the reported values for non-enzymatic $\mathrm{D}_{2}$-Lin oxidation in solution (kinetic isotope effect of approximately six-fold) [25]. In this homogenous non-chain-reaction example [25], an equimolar composition of reactants provides a ROS moiety for every molecule of $\mathrm{D}_{2}$-Lin. However, in the heterogeneous membrane autoxidation chain reaction, neighbouring lipid peroxyl radicals carry out further peroxidations [19]. Thus, the presence of $\mathrm{D}_{2}$-Lin or $\mathrm{D}_{4}$ $\alpha \mathrm{Lnn}$ in yeast would be expected to slow the chain reactions of PUFA autoxidation. The strength of the radical itself may also play a role. It is possible that the D-PUFA radical

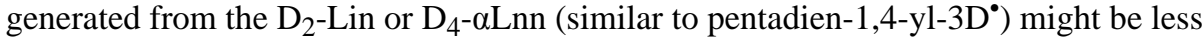
reactive than the equivalent standard PUFA radical (similar to a pentadien-1,4-yl-3H') [56,57]. This would be the case if the deuterium-containing radical was stabilized relative to hydrogen.

In contrast to the Q-less $\operatorname{coq}$ mutants, we found wild-type yeast are quite resistant to treatment with exogenously added PUFAs, consistent with previous results [30,52]. $S$. cerevisiae conditionally expressing a $\Delta 12$ fatty acid desaturase (from the rubber plant Hevea brasiliensis) can be induced to form palmitoleic, C16:2(n-6) and Lin [58]. The presence of these endogenously produced PUFAs did not alter yeast growth or morphology. However, the PUFA-synthesizing yeast did show increased sensitivity to oxidative stress, induced by treatment with paraquat, tert-butyl-hydroperoxide or hydrogen peroxide. Low levels of HNE modified protein adducts were detected in the PUFA-containing yeast (but not in wild-type yeast cells), and HNE levels increased following hydrogen peroxide-induced oxidative stress of the PUFA-containing yeast [58]. Yeast cells expressing the $\Delta 12$ fatty acid desaturase over the long term culture showed enhanced resistance or adaptation [59]. Such adaptation was shown to require peroxisomal catalase activity, consistent with the idea that resistance to oxidized PUFAs may require metabolism of lipid autoxidation products by yeast peroxisomes.

Our results presented here show that wild-type yeast subjected to heat stress $\left(37^{\circ} \mathrm{C}\right.$ or $\left.39^{\circ} \mathrm{C}\right)$ are rendered sensitive to PUFA treatment. Cells subjected to elevated temperature show accelerated mitochondrial respiration and enhanced ROS production $[41,60]$. Heat-induced ROS are thought to be responsible for cellular damage upon exposure to heat stress [61]. Wild-type yeast treated with Lin or $\alpha \mathrm{Lnn}$ are much more sensitive to heat stress as compared to untreated or Ole treated cells. In contrast, heat-stressed wild-type yeast are resistant to treatment with the isotope-reinforced $\mathrm{D}_{2}$-Lin or $\mathrm{D}_{4}-\alpha \mathrm{Lnn}$. Addition of exogenous antioxidants rescued heat-stressed PUFA-treated wild-type yeast, indicating that the toxicity derives from lipid autoxidation reactions. These results suggest that the protection afforded by the isotope reinforced PUFAs is not unique to the coq mutant yeast, but is rather a general property that can be extended to stressed cells containing a normal complement of antioxidant defence mechanisms.

Recent studies show that Lin or $\alpha \mathrm{Lnn}$ provided exogenously to yeast are present in mitochondrial lipids, including phosphatidyl choline, phosphatidyl ethanolamine and 
cardiolipin [62,63]. Mitochondria isolated from PUFA-treated wild-type yeast and subjected to ferrous-induced stress, showed enhanced lipid peroxidation products as compared to mitochondria isolated from untreated yeast [62]. In these same PUFA-laden yeast mitochondria, decreased electron transfer was observed mainly at cytochrome $b$ in complex III, and ROS was attributed to an electron leak at the Qo site of complex III [62]. Although wild-type yeast were not killed by PUFA-treatment under standard culture conditions, yeast mutants with dysregulation of lipid metabolism were hypersensitive [63]. For example yeast mutants harboring multiple defects in esterification of free fatty acids and sterols were profoundly sensitive to treatment with Lin or alpha-Lnn as compared to Ole [63]. Evaluating the protection afforded by isotope reinforced PUFAs in this lipid dysregulation model might help to distinguish the toxicity resulting from lipid peroxidation, from the lipotoxic effects elicited by "unsaturated fatty acid overload" [64].

Lin and $\alpha$ Lnn are essential fatty acids for animals. Thus animals should have the mechanisms in place to assimilate isotope reinforced $D_{2}$-Lin and $D_{4}-\alpha \operatorname{Lnn}$ provided as supplements. The results obtained here suggest a potential medicinal application for the reinforced PUFAs in cases where oxidative stress is involved in disease aetiology.

\section{Supplementary Material}

Refer to Web version on PubMed Central for supplementary material.

\section{Acknowledgments}

We thank Jeffrey Roth for technical assistance, and Drs. Robert Molinari, Aubrey DeGrey, Alexander TuckerSchwartz, and Charles Cantor for advice and assistance. This work was supported by a grant from the National Institutes of Health General Medical Sciences award GM45952 (to C.F.C.).

\begin{tabular}{|c|c|}
\hline \multicolumn{2}{|l|}{ Abbreviations } \\
\hline$\alpha \mathbf{L n n}$ & alpha-linolenic acid (C18:3, n-3) \\
\hline D & deuterium \\
\hline$D_{4}-\alpha \operatorname{Lnn}$ & $11,11,14,14-\mathrm{D}_{4}$-alpha-linolenic acid \\
\hline GC-MS & gas chromatography-mass spectrometry \\
\hline HHE & 4-hydroxy-hexenal \\
\hline HNE & 4-hydroxy-nonenal \\
\hline IE & isotope effect \\
\hline Lin & linoleic acid $(C 18: 2, n-6)$ \\
\hline $\mathrm{D}_{2}$-Lin & $11,11-\mathrm{D}_{2}$-linoleic acid \\
\hline MDA & malonic dialdehyde \\
\hline Ole & oleic acid (C18:1, n-9) \\
\hline PUFA & polyunsaturated fatty acid \\
\hline $\mathbf{Q}$ & coenzyme $\mathrm{Q}$ or ubiquinone \\
\hline $\mathbf{Q H}_{2}$ & coenzyme $\mathrm{QH}_{2}$ or ubiquinol \\
\hline ROS & reactive oxygen species \\
\hline YPD & rich growth medium with dextrose \\
\hline
\end{tabular}




\section{References}

1. Halliwell, B.; Gutteridge, JMC. Free Radicals in Biology and Medicine. New York, NY: Oxford University Press; 2007.

2. Bindoli A. Lipid peroxidation in mitochondria. Free Radic Biol Med 1988;5:247-261. [PubMed: 3075952]

3. Pamplona R. Membrane phospholipids, lipoxidative damage and molecular integrity: a causal role in aging and longevity. Biochim Biophys Acta 2008;1777:1249-1262. [PubMed: 18721793]

4. Orrenius S, Gogvadze V, Zhivotovsky B. Mitochondrial oxidative stress: implications for cell death. Annu Rev Pharmacol Toxicol 2007;47:143-183. [PubMed: 17029566]

5. Niki E. Lipid peroxidation: physiological levels and dual biological effects. Free Radic Biol Med 2009;47:469-484. [PubMed: 19500666]

6. Dobretsov GE, Borschevskaya TA, Petrov VA, Vladimirov YA. The increase of phospholipid bilayer rigidity after lipid peroxidation. FEBS Lett 1977;84:125-128. [PubMed: 590513]

7. Lim P, Wuenschell GE, Holland V, Lee DH, Pfeifer GP, Rodriguez H, Termini J. Peroxyl radical mediated oxidative DNA base damage: implications for lipid peroxidation induced mutagenesis. Biochemistry 2004;43:15339-15348. [PubMed: 15581346]

8. Bacot S, Bernoud-Hubac N, Baddas N, Chantegrel B, Deshayes C, Doutheau A, Lagarde M, Guichardant M. Covalent binding of hydroxy-alkenals 4-HDDE, 4-HHE, and 4-HNE to ethanolamine phospholipid subclasses. J Lipid Res 2003;44:917-926. [PubMed: 12588949]

9. Long EK, Picklo MJ Sr. Trans-4-hydroxy-2-hexenal, a product of $n-3$ fatty acid peroxidation: make some room HNE. Free Radic Biol Med 2010;49:1-8. [PubMed: 20353821]

10. Pillon NJ, Soulere L, Vella RE, Croze M, Care BR, Soula HA, Doutheau A, Lagarde M, Soulage CO. Quantitative structure-activity relationship for 4-hydroxy-2-alkenal induced cytotoxicity in L6 muscle cells. Chem Biol Interact 2010;188:171-180. [PubMed: 20619253]

11. Schug ZT, Gottlieb E. Cardiolipin acts as a mitochondrial signalling platform to launch apoptosis. Biochim Biophys Acta 2009;1788:2022-2031. [PubMed: 19450542]

12. Danial NN, Korsmeyer SJ. Cell death: critical control points. Cell 2004;116:205-219. [PubMed: 14744432]

13. Brigelius-Flohe R. Vitamin E: the shrew waiting to be tamed. Free Radic Biol Med 2009;46:543554. [PubMed: 19133328]

14. Zimniak P. Detoxification reactions: relevance to aging. Ageing Res Rev 2008;7:281-300. [PubMed: 18547875]

15. Packer L, Cadenas E. Oxidants and antioxidants revisited. New concepts of oxidative stress. Free Radic Res 2007;41:951-952. [PubMed: 17729110]

16. Salganik RI. The benefits and hazards of antioxidants: controlling apoptosis and other protective mechanisms in cancer patients and the human population. J Am Coll Nutr 2001;20:464S-472S. discussion 473S-475S. [PubMed: 11603657]

17. Calabrese EJ, Bachmann KA, Bailer AJ, Bolger PM, Borak J, Cai L, Cedergreen N, Cherian MG, Chiueh CC, Clarkson TW, Cook RR, Diamond DM, Doolittle DJ, Dorato MA, Duke SO, Feinendegen L, Gardner DE, Hart RW, Hastings KL, Hayes AW, Hoffmann GR, Ives JA, Jaworowski Z, Johnson TE, Jonas WB, Kaminski NE, Keller JG, Klaunig JE, Knudsen TB, Kozumbo WJ, Lettieri T, Liu SZ, Maisseu A, Maynard KI, Masoro EJ, McClellan RO, Mehendale HM, Mothersill C, Newlin DB, Nigg HN, Oehme FW, Phalen RF, Philbert MA, Rattan SI, Riviere JE, Rodricks J, Sapolsky RM, Scott BR, Seymour C, Sinclair DA, Smith-Sonneborn J, Snow ET, Spear L, Stevenson DE, Thomas Y, Tubiana M, Williams GM, Mattson MP. Biological stress response terminology: Integrating the concepts of adaptive response and preconditioning stress within a hormetic dose-response framework. Toxicol Appl Pharmacol 2007;222:122-128. [PubMed: 17459441]

18. Bowry VW, Stocker R. Tocopherol-mediated peroxidation. The prooxidant effect of viatmin E on the radical-initiated oxidation of human low-density lipoprotein. J Amer Chem Soc 1993;115:6029-6044.

19. Porter NA. Mechanisms for the autoxidation of polyunsaturated lipids. Accounts Chem Res 1986;19:262-268. 
20. Shchepinov MS. Reactive oxygen species, isotope effect, essential nutrients, and enhanced longevity. Rejuvenation Res 2007;10:47-59. [PubMed: 17378752]

21. Shchepinov MS. Do "heavy" eaters live longer? Bioessays 2007;29:1247-1256. [PubMed: 18027392]

22. Bigeleisen J. The validity of the use of tracers to follow chemical reactions. Science 1949;110:1416. [PubMed: 17753813]

23. Knapp MJ, Rickert K, Klinman JP. Temperature-dependent isotope effects in soybean lipoxygenase-1: correlating hydrogen tunneling with protein dynamics. J Am Chem Soc 2002;124:3865-3874. [PubMed: 11942823]

24. Jacquot C, Peng S, van der Donk WA. Kinetic isotope effects in the oxidation of arachidonic acid by soybean lipoxygenase-1. Bioorg Med Chem Lett 2008;18:5959-5962. [PubMed: 18793849]

25. Kitaguchi H, Ohkubo K, Ogo S, Fukuzumi S. Additivity rule holds in the hydrogen transfer reactivity of unsaturated fatty acids with a peroxyl radical: mechanistic insight into lipoxygenase. Chem Commun (Camb) 2006:979-981. [PubMed: 16491182]

26. Tran UC, Clarke CF. Endogenous synthesis of coenzyme Q in eukaryotes. Mitochondrion 2007;7S:S62-S71. [PubMed: 17482885]

27. Bentinger M, Brismar K, Dallner G. The antioxidant role of coenzyme Q. Mitochondrion 2007;7S:S41-S50. [PubMed: 17482888]

28. Paltauf F, Daum G. Phospholipid transfer proteins from yeast. Methods Enzymol 1992;209:514522. [PubMed: 1495431]

29. Bossie MA, Martin CE. Nutritional regulation of yeast delta-9 fatty acid desaturase activity. J Bacteriol 1989;171:6409-6413. [PubMed: 2687232]

30. Do TQ, Schultz JR, Clarke CF. Enhanced sensitivity of ubiquinone deficient mutants of Saccharomyces cerevisiae to products of autooxidized polyunsaturated fatty acid. Proc Natl Acad Sci USA 1996;93:7534-7539. [PubMed: 8755509]

31. Poon WW, Do TQ, Marbois BN, Clarke CF. Sensitivity to treatment with polyunsaturated fatty acids is a general characteristic of the ubiquinone-deficient yeast $\operatorname{coq}$ mutants. Molec Aspects Med 1997;18:s121-s127. [PubMed: 9266513]

32. Tucker WP, Tove SB, Kepler CR. The synthesis of 11,11-Dideuterolinoleic acid. J Labelled Compounds 1970;7:11-15.

33. Meyer MP, Klinman JP. Synthesis of linoleic acids combinatorially-labeled at the vinylic positions as substrates for lipoxygenases. Tetrahedron Lett 2008;49:3600-3603. [PubMed: 19543446]

34. Osbond JM, Philpott PG, Wickens JC. Essential fatty acids. Part I. Synthesis of Linoleic, gammalinolenic, arachidonic, and docaso-4,7,10,13,16-pentaenoic acid. J Chem Soc 1961:2779-2787.

35. Marbois BN, Clarke CF. The COQ7 gene encodes a protein in Saccharomyces cerevisiae necessary for ubiquinone biosynthesis. J Biol Chem 1996;271:2995-3004. [PubMed: 8621692]

36. Johnson A, Gin P, Marbois BN, Hsieh EJ, Wu M, Barros MH, Clarke CF, Tzagoloff A. COQ9, a new gene required for the biosynthesis of coenzyme $\mathrm{Q}$ in Saccharomyces cerevisiae. J Biol Chem 2005;280:31397-31404. [PubMed: 16027161]

37. Burke, D.; Dawson, D.; Stearns, T. Methods in Yeast Genetics. Plainview, NY: Cold Spring Harbor Laboratory Press; 2000.

38. Moss CW, Lambert MA, Merwin WH. Comparison of rapid methods for analysis of bacterial fatty acids. Appl Microbiol 1974;28:80-85. [PubMed: 4844271]

39. Shaw WHC, Jefferies JP. Determination of ergosterol in yeast. Anal Chem 1953;25:1130.

40. Orlandi I, Bettiga M, Alberghina L, Nystrom T, Vai M. Sir2-dependent asymmetric segregation of damaged proteins in ubp10 null mutants is independent of genomic silencing. Biochim Biophys Acta 2010;1803:630-638. [PubMed: 20211662]

41. Davidson JF, Schiestl RH. Mitochondrial respiratory electron carriers are involved in oxidative stress during heat stress in Saccharomyces cerevisiae. Mol Cell Biol 2001;21:8483-8489. [PubMed: 11713283]

42. Buettner GR. The pecking order of free radicals and antioxidants: lipid peroxidation, alphatocopherol, and ascorbate. Arch Biochem Biophys 1993;300:535-543. [PubMed: 8434935] 
43. Xu L, Davis TA, Porter NA. Rate constants for peroxidation of polyunsaturated fatty acids and sterols in solution and in liposomes. J Am Chem Soc 2009;131:13037-13044. [PubMed: 19705847]

44. Yazu K, Yamamoto Y, Ukegawa K, Niki E. Mechanism of lower oxidizability of eicosapentaenoate than linoleate in aqueous micelles. Lipids 1996;31:337-340. [PubMed: 8900464]

45. Yin H, Porter NA. New insights regarding the autoxidation of polyunsaturated fatty acids. Antioxid Redox Signal 2005;7:170-184. [PubMed: 15650406]

46. Negre-Salvayre A, Coatrieux C, Ingueneau C, Salvayre R. Advanced lipid peroxidation end products in oxidative damage to proteins. Potential role in diseases and therapeutic prospects for the inhibitors. Br J Pharmacol 2008;153:6-20. [PubMed: 17643134]

47. Davies AG. The Schenk rearrangement of allylic hydroperoxides. J Chem Res 2009;2009:533544.

48. Pryor WA, Stanley JP. Letter: A suggested mechanism for the production of malonaldehyde during the autoxidation of polyunsaturated fatty acids. Nonenzymatic production of prostaglandin endoperoxides during autoxidation. J Org Chem 1975;40:3615-3617. [PubMed: 1185332]

49. Esterbauer H, Schaur RJ, Zollner H. Chemistry and biochemistry of 4-hydroxynonenal, malonaldehyde and related aldehydes. Free Radic Biol Med 1991;11:81-128. [PubMed: 1937131]

50. Schneider C, Porter NA, Brash AR. Routes to 4-hydroxynonenal: fundamental issues in the mechanisms of lipid peroxidation. J Biol Chem 2008;283:15539-15543. [PubMed: 18285327]

51. Serhan CN. Novel eicosanoid and docosanoid mediators: resolvins, docosatrienes, and neuroprotectins. Curr Opin Clin Nutr Metab Care 2005;8:115-121. [PubMed: 15716788]

52. Black PN, DiRusso CC. Yeast acyl-CoA synthetases at the crossroads of fatty acid metabolism and regulation. Biochim Biophys Acta 2007;1771:286-298. [PubMed: 16798075]

53. Kushner DJ, Baker A, Dunstall TG. Pharmacological uses and perspectives of heavy water and deuterated compounds. Can J Physiol Pharmacol 1999;77:79-88. [PubMed: 10535697]

54. Sumner ER, Avery SV. Phenotypic heterogeneity: differential stress resistance among individual cells of the yeast Saccharomyces cerevisiae. Microbiology 2002;148:345-351. [PubMed: 11832498]

55. Catala A. Lipid peroxidation of membrane phospholipids generates hydroxy-alkenals and oxidized phospholipids active in physiological and/or pathological conditions. Chem Phys Lipids 2009;157:1-11. [PubMed: 18977338]

56. Elison C, Rapoport H, Laursen R, Elliott HW. Effect of deuteration of N--CH3 group on potency and enzymatic N-demethylation of morphine. Science 1961;134:1078-1079. [PubMed: 13889855]

57. Russell GA. Deuterium-isotope effects in the autoxidation of aralkyl hydrocarbons. Mechanism of the interaction of peroxy radicals. J Am Chem Soc 1957;79:3871-3877.

58. Cipak A, Hasslacher M, Tehlivets O, Collinson EJ, Zivkovic M, Matijevic T, Wonisch W, Waeg G, Dawes IW, Zarkovic N, Kohlwein SD. Saccharomyces cerevisiae strain expressing a plant fatty acid desaturase produces polyunsaturated fatty acids and is susceptible to oxidative stress induced by lipid peroxidation. Free Radic Biol Med 2006;40:897-906. [PubMed: 16520241]

59. Cipak A, Jaganjac M, Tehlivets O, Kohlwein SD, Zarkovic N. Adaptation to oxidative stress induced by polyunsaturated fatty acids in yeast. Biochim Biophys Acta 2008;1781:283-287. [PubMed: 18452720]

60. Salo DC, Donovan CM, Davies KJ. HSP70 and other possible heat shock or oxidative stress proteins are induced in skeletal muscle, heart, and liver during exercise. Free Radic Biol Med 1991;11:239-246. [PubMed: 1937141]

61. Abele D. Toxic oxygen: the radical life-giver. Nature 2002;420:27. [PubMed: 12422197]

62. Cortes-Rojo C, Calderon-Cortes E, Clemente-Guerrero M, Estrada-Villagomez M, Manzo-Avalos S, Mejia-Zepeda R, Boldogh I, Saavedra-Molina A. Elucidation of the effects of lipoperoxidation on the mitochondrial electron transport chain using yeast mitochondria with manipulated fatty acid content. J Bioenerg Biomembr 2009;41:15-28. [PubMed: 19224349]

63. Rockenfeller P, Ring J, Muschett V, Beranek A, Buettner S, Carmona-Gutierrez D, Eisenberg T, Khoury C, Rechberger G, Kohlwein SD, Kroemer G, Madeo F. Fatty acids trigger mitochondriondependent necrosis. Cell Cycle 2010;9:2836-2842. [PubMed: 20647757] 
64. Kohlwein SD. Obese and anorexic yeasts: experimental models to understand the metabolic syndrome and lipotoxicity. Biochim Biophys Acta 2010;1801:222-229. [PubMed: 20056167]

65. Bremer, M.; Doerge, RW. Statistics at the Bench: A Step-by-Step Handbook for Biologists. Cold Spring Harbor: Cold Spring Harbor Laboratory Press; 2010. 
A
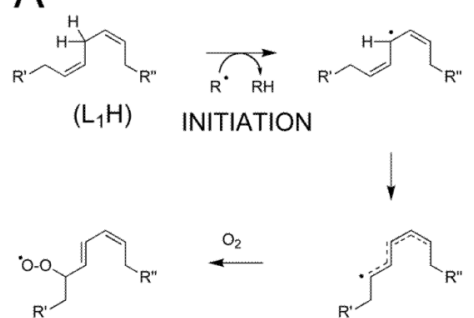

$C_{L_{2}}^{L_{2} \mathrm{H}}$ PROPAGATION

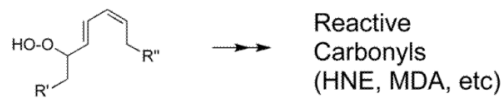

B<smiles>CCCCCCCCCCCCCCCCCCO</smiles><smiles>CCCCC/C=C\C/C=C\CCCCCCC(=O)O</smiles>

Lin

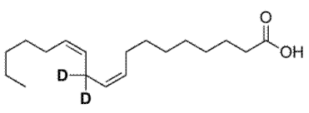

$11,11-D_{2}-$ Lin
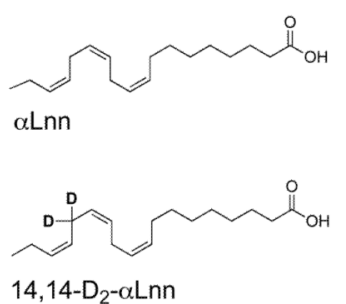

$14,14-D_{2}-\alpha \operatorname{Lnn}$

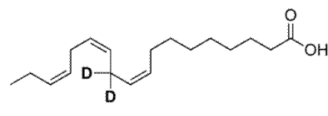

$11,11-\mathrm{D}_{2}-\alpha \mathrm{Lnn}$

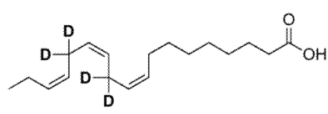

$11,11,14,14-D_{4}-\alpha \operatorname{Lnn}$

Fig. 1.

Lipid autoxidation reactions of PUFAs. (Panel $A$ ) The bis-allylic $\mathrm{H}$ atoms are subject to both initiation and propagation reactions of PUFA lipid autoxidation. (Panel B) Fatty acids used in this study. Ole, oleic acid (18:1, n-9; cis-9-octadecenoic acid); Lin, linoleic acid (18:2, n6; cis,cis-9,12-octadecadienoic acid); 11,11-- $\mathrm{D}_{2}$-Lin (11,11- $\mathrm{D}_{2}$-cis,cis-9,12-octadecadienoic acid); $\alpha$ Lnn, alpha-linolenic acid (18:3, n-3; cis,cis,cis-9,12,15-octadecatrienoic acid);

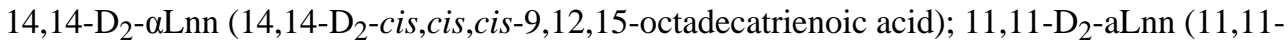
$\mathrm{D}_{2}$-cis,cis,cis-9,12,15-octadecatrienoic acid); $\mathrm{D}_{4}$ - $\alpha$ Lnn $\left(11,11,14,14-\mathrm{D}_{4}\right.$-cis,cis,cis-9,12,15octadecatrienoic acid). 


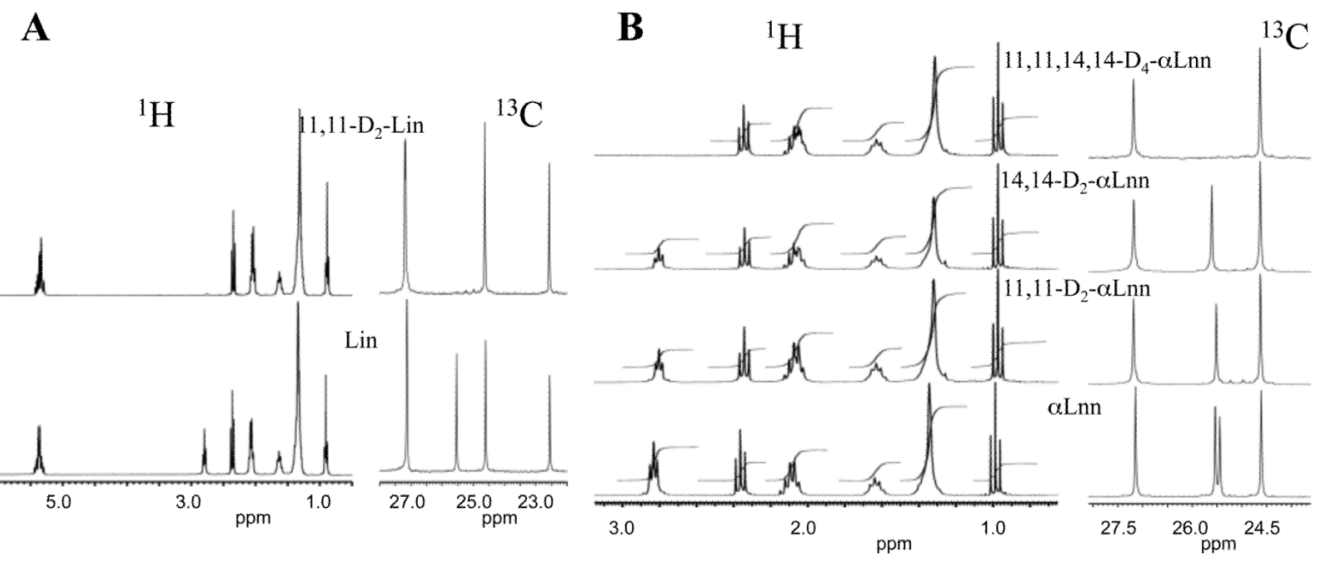

Fig. 2.

Characteristic areas of ${ }^{1} \mathrm{H}$ and ${ }^{13} \mathrm{C}$ spectra, all values in ppm. (Panel $A$ ) Deuteration of Lin acid at pos. 11 is confirmed by the disappearance of peaks in ${ }^{1} \mathrm{H}$ and ${ }^{13} \mathrm{C}$ NMR spectra. Disappearance of the peak at $\delta_{\mathrm{H}} 2.764$ is expected due to absence of $\mathrm{H}$ atoms $\left({ }^{1} \mathrm{H} \mathrm{NMR}\right)$. Disappearance of the peak at $\delta_{\mathrm{C}} 25.5$ is due to combination of Nuclear Overhauser Effect, and splitting of this particular carbon atom into a quintet by two D atoms in the deuterated form of Lin acid. (Panel B) The ${ }^{1} \mathrm{H}$ NMR spectrum shows that the $\mathrm{H}$ atoms at $\mathrm{C} 11$ and $\mathrm{C} 14$ positions of site-specifically deuterated $\alpha$ Lnn coincide $\left(\delta_{\mathrm{H}} 2.801\right)$ thus deuteration at either site $\left(11,11-\mathrm{H}_{2}, 14,14-\mathrm{D}_{2}\right.$ or $\left.11,11-\mathrm{D}_{2}, 14,14-\mathrm{H}_{2}\right)$ leads to a $50 \%$ decrease in integration of this peak, while deuteration of both sites $\left(11,11,14,14-\mathrm{D}_{4}\right)$ leads to the complete disappearance of the peak at $\delta_{\mathrm{H}} 2.801$. However, ${ }^{13} \mathrm{C}$ NMR experiments can clearly distinguish between the three deuterated forms, as the observed peaks for $\mathrm{C} 11$ and $\mathrm{C} 14$ positions are separated by a small but detectable difference. Thus, the deuteration at either $\mathrm{C} 11$ or $\mathrm{C} 14$ positions leads to disappearance of the peak at $\delta_{\mathrm{C}} 25.68$ or $\delta_{\mathrm{C}} 25.60$, respectively, while the deuteration at both sites leads to disappearance of the two corresponding peaks. 

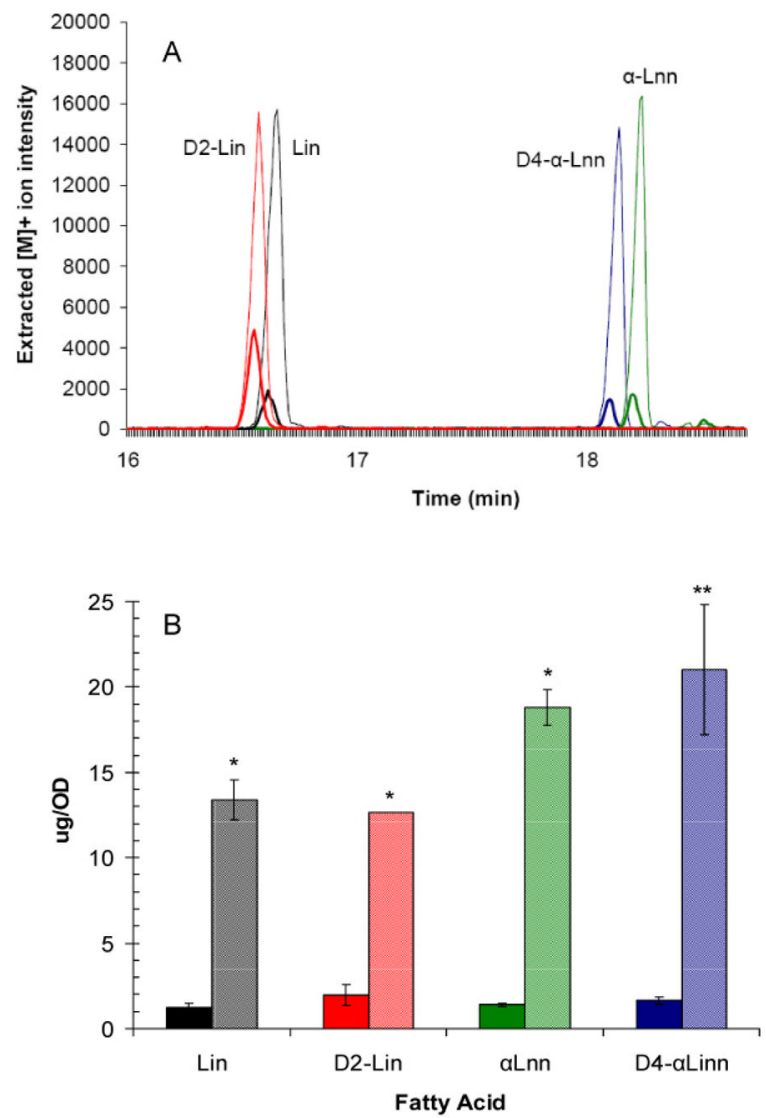

Fig. 3.

Uptake of exogenously supplied fatty acids by yeast. (Panel A) Chromatograms of the yeast extracts subjected to GC-MS analyses. Wild-type (W303) yeast were harvested at log phase and incubated in the presence of $200 \mu \mathrm{M}$ of the designated fatty acid (red, $\mathrm{D}_{2}$-Lin; black, $\mathrm{Lin}$; blue, $\mathrm{D}_{4}-\alpha \mathrm{Lnn} ;$ green, $\left.\alpha \mathrm{Lnn}\right)$ for either $0 \mathrm{~h}$ (bold trace) or $4 \mathrm{~h}$ (thin trace). Yeast cells were harvested, washed twice with sterile water and then subjected to alkaline methanolysis and saponification, lipid extraction, and separation and detection by GC-MS as described in SI Methods. Eight chromatograms are superimposed, and denote the $0 \mathrm{~h}$ and $4 \mathrm{~h}$ treatments with the designated fatty acids. Panel $B$ : The peak areas of each of the FAMEs corresponding to Lin, $\mathrm{D}_{2}$ - $\mathrm{Lin}, \alpha \mathrm{Lnn}$, and $\mathrm{D}_{4}-\alpha \mathrm{Lnn}$ (bold or light colors designate FAME and time as shown in panel A) were corrected for the recovery of the C17:0 internal standard, and quantified with a calibration curve. Two aliquots of yeast cells at each time point $(0 \mathrm{~h}$, bold color; $4 \mathrm{~h}$, light color) were processed for determinations of FAMES, and the quantity is depicted as average \pm S.D. The FAME content is significantly different at $4 \mathrm{~h}$ compared to $0 \mathrm{~h}$ as determined by the two sample $\mathrm{t}$ test [65]; *, $\mathrm{p}<0.01$; **, $\mathrm{p}<0.05$. Results are representative of two independent experiments. 


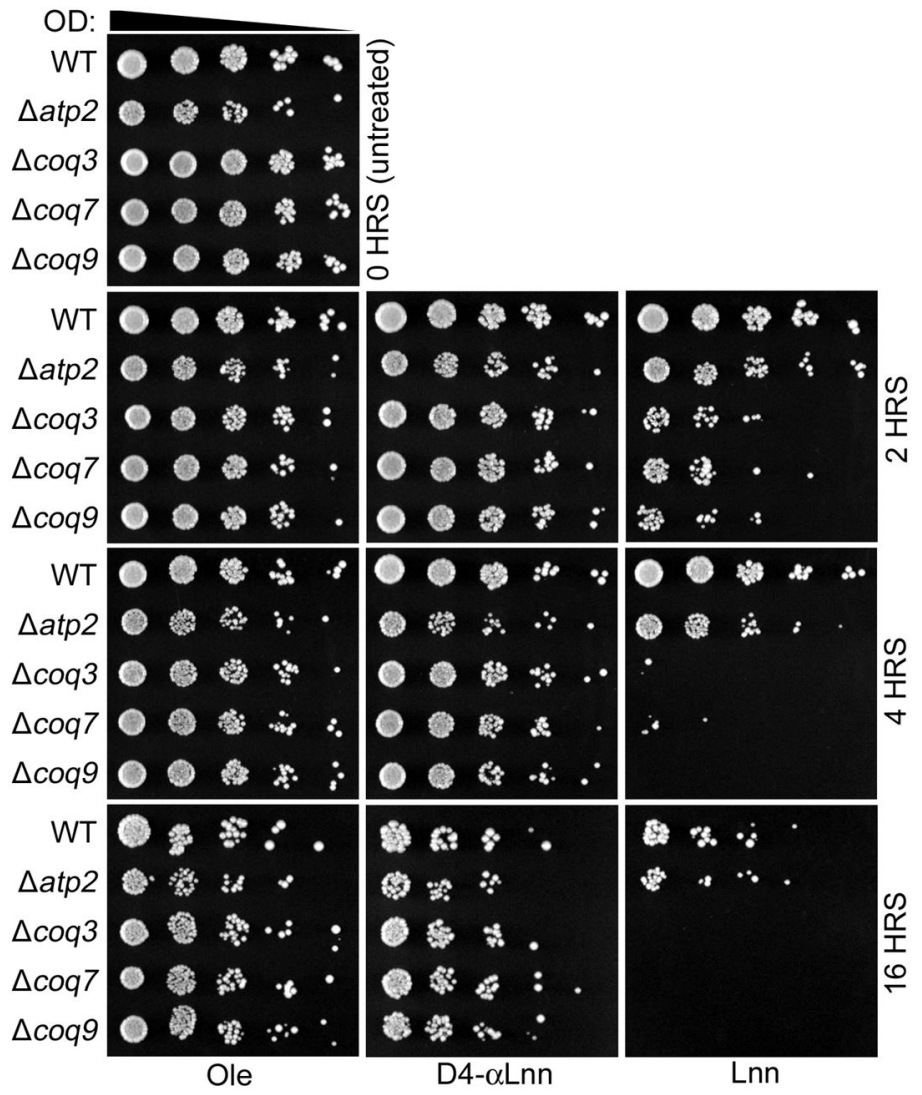

Fig. 4.

Sensitivity of $\operatorname{coq}$ null mutants to treatment with $\alpha \mathrm{Lnn}$ is abrogated by isotopereinforcement. Yeast Q-less $\operatorname{coq} 3$, coq7, and $\operatorname{coq} 9$ null mutants, or the Q-replete respiratory deficient atp2 null mutant, were grown in YPD medium and harvested while in log phase growth $\left(\mathrm{OD}_{600 \mathrm{~nm}}=0.1-1 \cdot 0\right)$. Cells were washed twice with sterile water and resuspended in phosphate buffer ( $0.10 \mathrm{M}$ sodium phosphate, $\mathrm{pH} 6.2,0.2 \%$ dextrose) to an $\mathrm{OD}_{600 \mathrm{~nm}}=0.2$. Samples were removed and 1:5 serial dilutions starting at $0.20 \mathrm{OD} / \mathrm{ml}$ were spotted on YPD plate medium, to provide a zero time untreated control (top left panel). The designated fatty acids were added to $200 \mu \mathrm{M}$ final concentration to $20 \mathrm{ml}$ of yeast in phosphate buffer. At 2 $\mathrm{h}, 4 \mathrm{~h}$, and $16 \mathrm{~h}$ samples were removed, 1:5 serial dilutions prepared, and spotted onto YPD plate medium. Pictures were taken after 2 days of growth at $30^{\circ} \mathrm{C}$. This panel is representative of two independent assays. 


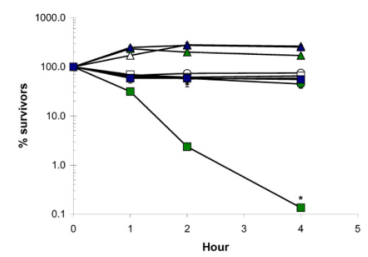

Fig. 5.

Yeast coq3 mutants treated with isotope-reinforced $\mathrm{D}_{4}-\alpha \mathrm{Lnn}$ are profoundly resistant to PUFA-mediated cell killing. The fatty acid sensitivity assay was performed as described in Fig. 4 except that three $100 \mu \mathrm{l}$ aliquots were removed at 1,2 , and $4 \mathrm{~h}$ and, following dilution, spread onto YPD plates. Pictures were taken after 2 to 2.5 days, and the number of colony forming units (CFU) determined the percent survival (average \pm S.D.). Yeast strains include wild type (circles), atp2 (triangles), or coq3 (squares); Fatty acid treatments are designated by color, and include Ole (white); $\alpha \mathrm{Lnn}$ (green); or $\mathrm{D}_{4^{-}} \alpha \mathrm{Lnn},($ blue). The number of CFU in $\alpha$ Lnn-treated $\operatorname{coq} 3$ mutant yeast at $4 \mathrm{~h}$ is significantly different as compared to the $\mathrm{D}_{4}$ - $\alpha \mathrm{Lnn}$ treated $\operatorname{coq} 3$ mutant yeast as determined by the two sample $\mathrm{t}$ test [65]; ${ }^{*}, \mathrm{p}<0.001$. Results are representative of two independent experiments. 


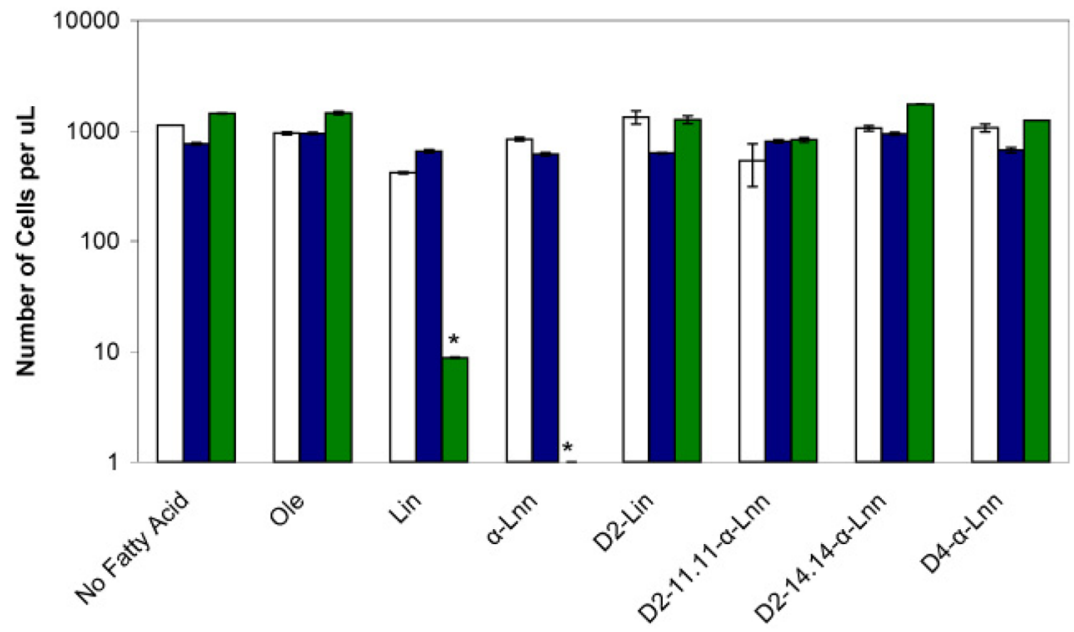

Fig. 6.

Sensitivity of $\operatorname{coq}$ null mutants to treatment with Lin or $\alpha$ Lnn acids is abrogated by either complete or partial isotope reinforcement. Yeast sample preparation and statistical analyses were as described in Fig. 5. Three aliquots of the designated yeast strains (wild type, white; atp 2, blue; coq3, green) were removed following incubation $\left(10 \mathrm{~h}, 30^{\circ} \mathrm{C}\right)$ with either No Fatty Acid; Ole; Lin; $\alpha$ Lnn; $D_{2}$-Lin; $11,11-D_{2}-\alpha \operatorname{Lnn} ; 14,14-D_{2}-\alpha \operatorname{Lnn}$ or $\mathrm{D}_{4}-\alpha \operatorname{Lnn}$. The chart shows the CFU per $\mu$ l (average \pm S.D.). The number of surviving coq3 mutant cells is significantly different as compared to wild type or atp 2 mutants $(*, p<0.0007)$. Results are representative of two independent experiments. 

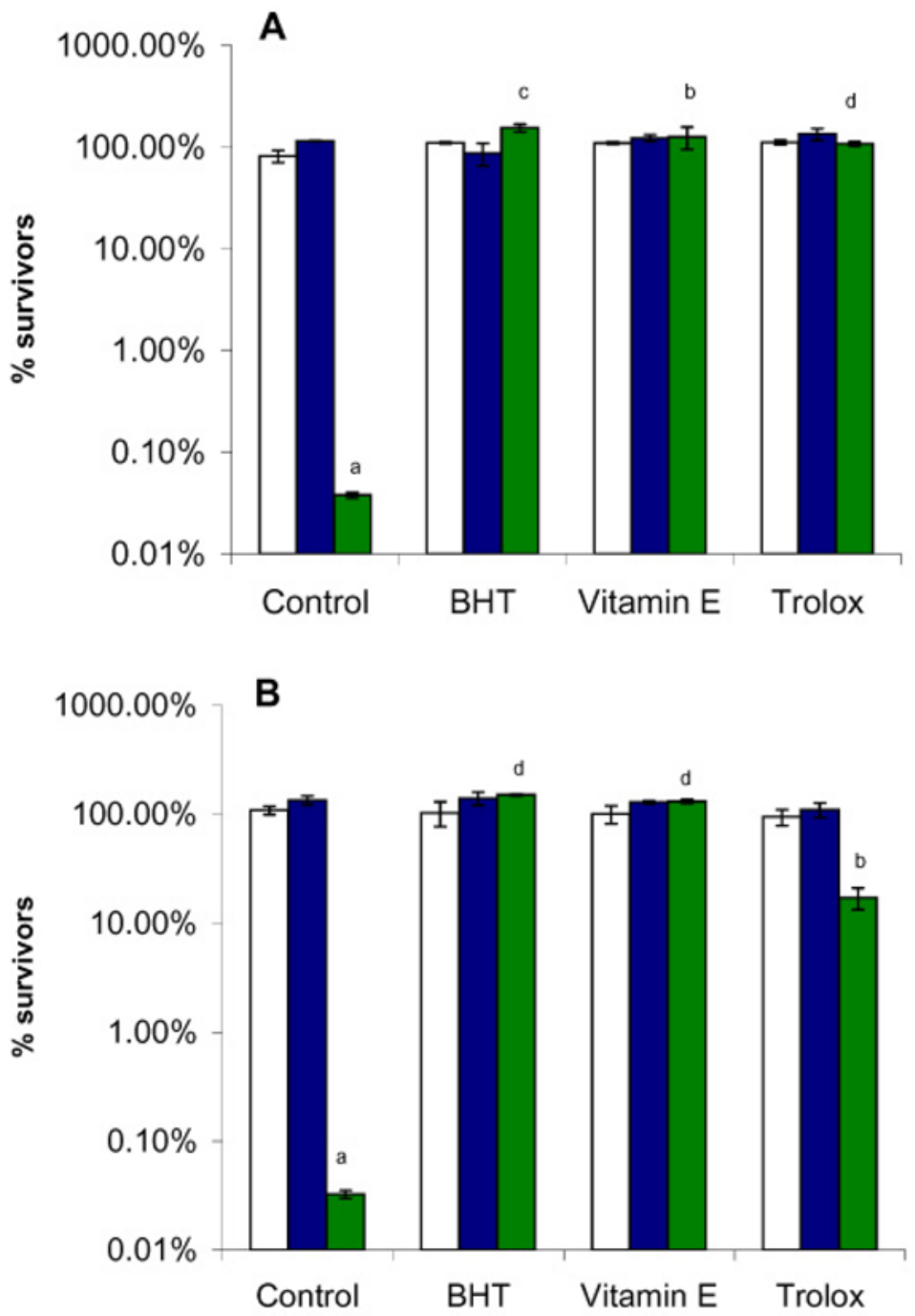

Fig. 7.

Antioxidants rescue the hypersensitivity of the yeast $\operatorname{coq} 3$ null mutant to Lin or $\alpha \mathrm{Lnn}$ treatment. Yeast sample preparation and statistical analyses were as described in Fig. 5, except that $200 \mu \mathrm{M}$ of the designated antioxidants were added prior to the addition of 200 $\mu \mathrm{M}$ Lin $($ Panel A) or $200 \mu \mathrm{M} \alpha \mathrm{Lnn}$ (Panel B). Three $100 \mu \mathrm{l}$ aliquots were removed at $4 \mathrm{~h}$, and dilutions were prepared and spread onto YPD plates. The number of CFU in untreated wild-type cells was set at $100 \%$. Yeast strains included wild type (white), corl null (blue), or coq3 null (green). The number of surviving coq3 mutant cells is significantly different as compared to wild type or corl mutants (PUFA treatment control; $a, \mathrm{p}<0.002$ ). Antioxidants afford significant rescue of the coq3 mutant hypersensitivity to PUFA treatment $(b, \mathrm{p}<$ $0.002 ; c, \mathrm{p}<0.00021 ; d, \mathrm{p}<0.000025)$. Results are representative of three independent experiments. 


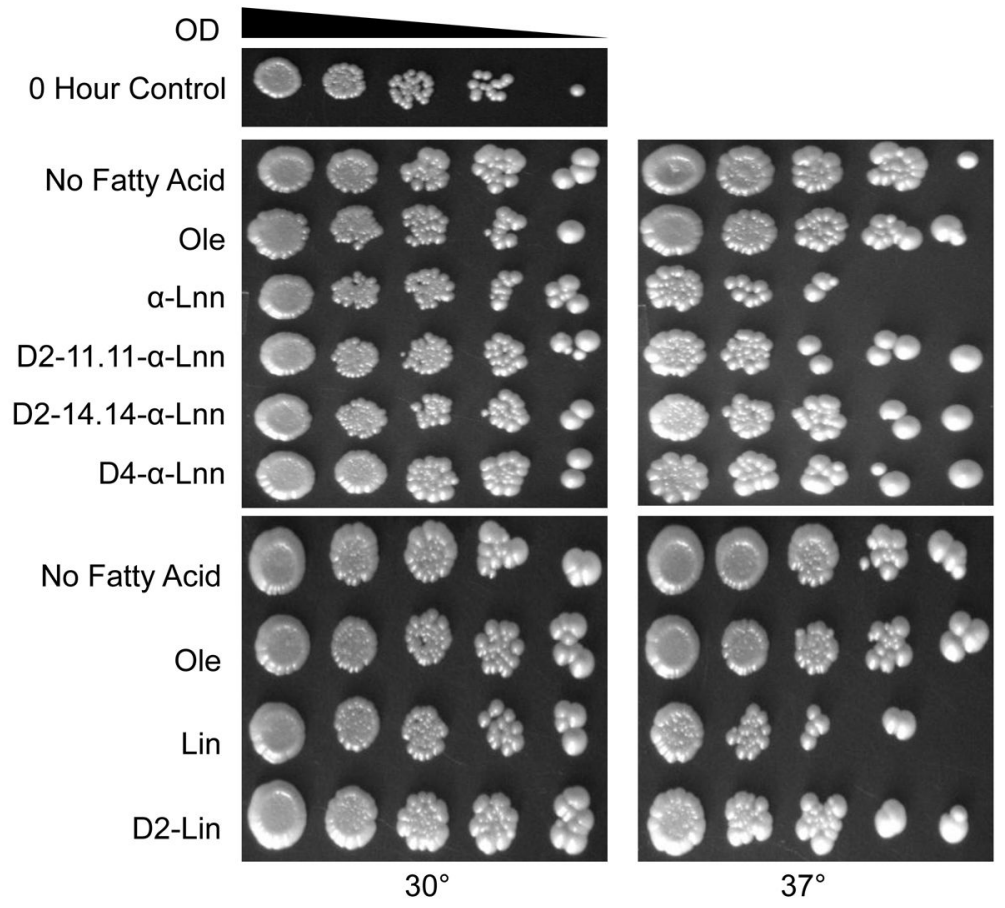

Fig. 8.

Heat stressed wild-type yeast are sensitive to standard PUFAs but resistant to treatment with isotope-reinforced PUFAs. Yeast sample preparation was as described in Fig. 4, except that incubations with the designated fatty acids proceeded for $5 \mathrm{~h}$ at either $30^{\circ} \mathrm{C}$ or $37^{\circ} \mathrm{C}$, and dilutions were plated on YPD. A zero h control is shown at the top. Results are representative of two independent experiments. 


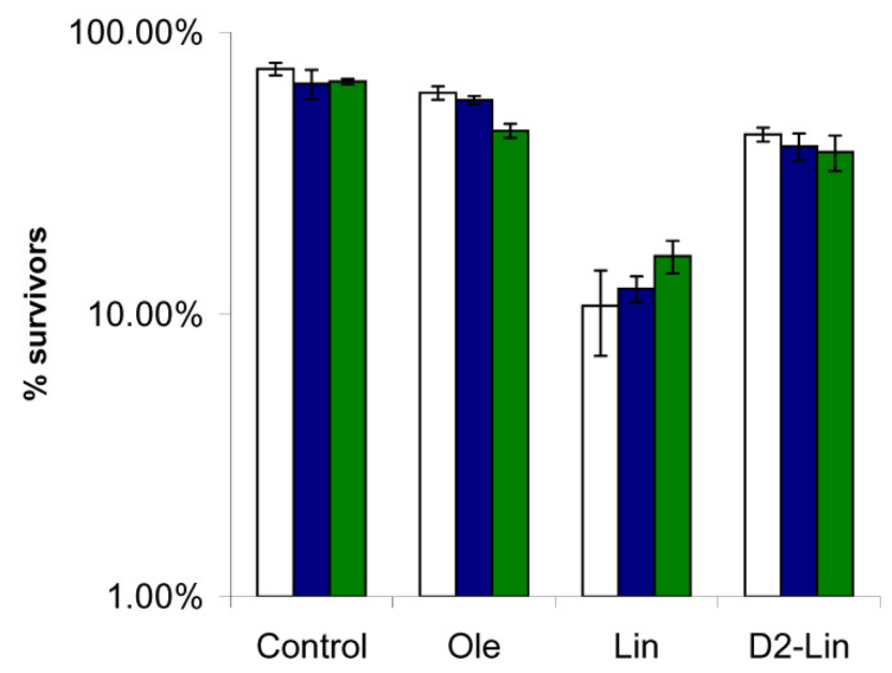

Fig. 9.

Heat stressed wild-type yeast are sensitive to PUFA-mediated oxidative stress as measured by colony survival on different carbon sources. Yeast sample preparation was as described in Fig. 8, except that incubations with the designated fatty acids proceeded for $2 \mathrm{~h}$ at $39{ }^{\circ} \mathrm{C}$. Three $100 \mu$ l aliquots were removed, and dilutions were prepared and were plated on YPD (white), YPG (blue), or YPE (green) solid media to determine CFU (average \pm S.D.). The number of CFU in untreated wild-type cells was set at $100 \%$. 


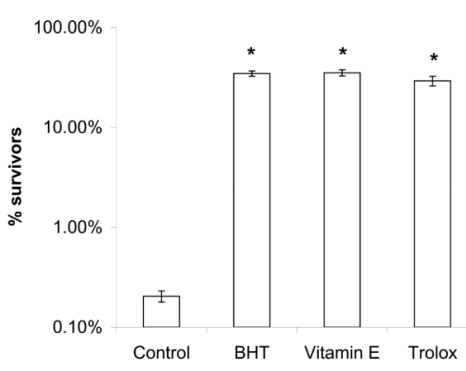

Fig. 10.

Antioxidants rescue the sensitivity of wild-type yeast to heat stress plus PUFA treatment. Wild-type were treated as described in Fig. 9, except that $200 \mu \mathrm{M}$ of the designated antioxidants were added prior to the addition of $200 \mu \mathrm{M}$ Lin. Three $100 \mu \mathrm{l}$ aliquots were removed at $3 \mathrm{~h}$, and dilutions were prepared and spread onto YPD plates to determine CFU (average \pm S.D.). Antioxidants afford significant rescue of the wild-type sensitivity to Lin treatment $(*, p<0.0001)$. Statistical analyses were as described in Fig. 5. Results are representative of two independent experiments. 